UDK $630 * 23: 582.681 .81$

$582.681 .81: 630 * 6$

\title{
ANALIZA KOMERCIJALNE ISPLATIVOSTI ZASADA TOPOLA STAROSTI 29 GODINA PRIMENOM METODA INVESTICIONE KALKULACIJE*
}

\section{Analysis of commercial profitability of poplar plantations aged 29 years applying some methods of investment calculation}

\author{
Keča Ljiljana ${ }^{1}$, Ranković Nenad ${ }^{1}$, Pajić Sanja ${ }^{2}$
}

\begin{abstract}
In the conditions of the increasing wood consumption and demand in the world, there is an aim of majority of national economy to intensify local resource production. Poplar wood has a lot of comparative behalf and wide usage values, and today is recognized in a different ways in wood processing industry. It is also very important as substitute for wood of other more valuable tree species.

Production of poplar wood requires rational and planned management, so that the site and the species potential are maximally utilised, on the one hand and on the other hand also to realise the favourable financial effects. In this sense, costs and receipts of wood production of the clonal poplar I-214 were investigated in the Management Unit „Rađenovići Novi“, 20a, (FE „Sremska Mitrovica“). The stand 29 years old, planting density 6x6 $\mathrm{m}$, forest type poplar on semigley alluvium.

The commercial profitability of poplar cultivation was analysed in an artificial poplar plantation, rotation 29 years. The aim of the study was to check the justification of the invested financial means in artificial poplar plantations, based on the analysis of costs and receipts in the period of 29 years, by using the method of analysis of commercial profitability, especially some methods of dynamic investment calculation.
\end{abstract}

Key words: commercial profitability, poplar, costs, receipts

\section{Izvod}

Apstrakt: U uslovima rastuće potražnje za drvetom u svetu, većina nacionalnih ekonomija intenzivira proizvodnju drveta iz sopstvenih resursa. Drvo topole se na tom putu nalazi kao veoma pogodno zbog svojih komparativnih prednosti u odnosu na

\footnotetext{
* Rad prezentiran na međunarodnoj naučnoj Konferenciji "Šumarska nauka između ekonomije i zahtjeva društva", povodom 60. godišnjice Šumarskog fakulta Univerziteta u Sarajevu, Sarajevo, hotel "Hollywood" 8 - 10.10.2008. godine

${ }^{1}$ Sumarski fakultet Univerziteta u Beogradu, Srbija - University of Belgrade, Faculty of Forestry, Serbia

${ }^{2}$ PE "Vojvodinašume", Petrovaradin, FE "Sremska Mitrovica”, Sremska Mitrovica
} 
druge vrste drveta. Važno je napomenuti da se drvo topole pojavljuje kao dragocen supstitut drugim, vrednijim vrstama drveta.

Proizvodnja drveta topole zahteva racionalno i dobro planirano upravljanje, kako bi se potencijali staništa i vrste maksimalno iskoristili a sa druge strane postigli zadovoljavajući finansijski efekti. U tom smislu proučeni su troškovi i prihodi proizvodnje drveta klonske topole I-214, u okviru gazdinske jedinice Rađenovići Novi 20a (JP „Vojvodinašume“, Sremska Mitrovica). Sastojina je starosti 29 godina, gustina sadnje 6X6, tip šume topole na semigleju.

$\mathrm{U}$ radu je analizirana komercijalna isplativost plantažnog uzgoja topola, ophodnje 29 godina. Cilj rada je da se prikaže opravdanost investiranja finansijskih sredstava $u$ veštačke zasade topole, bazirano je na analizi troškova i prihoda u toku 29 godina i to korišćenjem proračuna metoda komercijalne isplativosti, posebno dinamičkih metoda za proračun investiocionih ulaganja.

Ključne reči: komercijalna profitabilnost, topola, troškovi, prihodi

\section{UVOD - Introduction}

Topole spadaju u jednu od najproduktivnijih vrsta drveća kod nas. Složenost proizvodnje drveta topole zahteva plansko i racionalno vođenje, kako bi se potencijali staništa i same vrste maksimalno koristili. U Jugoslaviji je topolarstvo doživelo svoju ekspanziju 50-ih godina XX veka. Kako topole poseduju niz komparativnih prednosti u odnosu na neke druge vrste drveta (znatno kraći ciklus proizvodnje, brže vraćanje uloženih sredstava, relativno visoki prinosi i sl.) (PUDAR, 1982) atraktivnost njihove proizvodnje i uzgoja se zadržala u šumarskoj praksi do danas.

U takvoj situaciji podizanje plantaža i kultura topola kod nas ima izražen privredni značaj, jer se ulaganjem sredstava u realizaciju ovakvih projekata stvara proizvodna osnova koja omogućava ostvarivanje određenih prihoda. Kako se šumarski projekat može definisati kao investiciona aktivnost trošenja sredstava (kapitala), od koje možemo da očekujemo ostvarivanje dohotka u određenom vremenskom periodu (GREGERSEN, CONTRERAS, 1979), u topolarstvu je ovaj period znatno kraći nego kod ostalih drvenastih vrsta, pa je i realizacija ovakvih projekata opravdana sa finansijskog stanovišta, pod određenim uslovima.

$\mathrm{Na}$ osnovu prethodno proučene teoretske građe, koja se odnosi na vrednovanje investicionog projekta i njegovu komercijalnu isplativost, istraživani su troškovi i prihodi klonske topole I-214 u gazdinskoj jedinici „Rađenovići Novi“, odeljenje 20, odsek „a“ (ŠG „Sremska Mitrovica“) (Slika 1) površine od oko 29 ha. U pitanju je sastojina stara 29 godine, sa sadnjom $6 \times 6 \mathrm{~m}$, tip šume topole na aluvijalnom semigleju. Lokalitet se nalazi u blizini obale reke Save, gde je primenjena potpuna tehnologija podizanja i uzgoja zasada topole. Radi se o šumskoj kulturi koja je očuvana i čija je osnovna namena proizvodnja tehničkog drveta. 


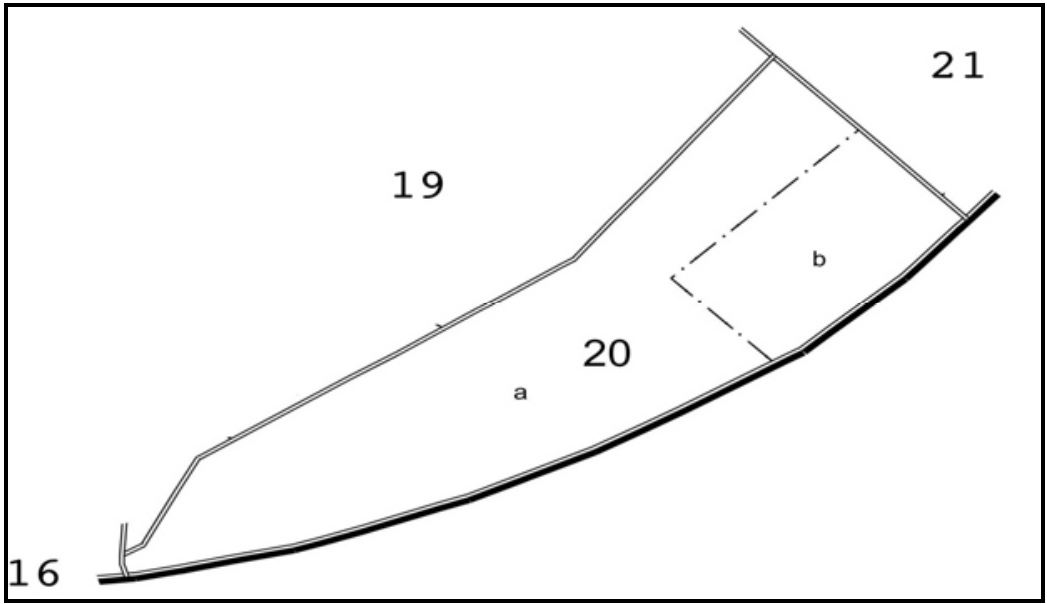

Slika 1. Gazdinska jedinica „Rađenovci Novi“, odeljenje 20

Figure 1. Management Unit „Rađenovci Novi“, compartment 20

Predmet istraživanja su finansijski elementi procesa proizvodnje veštački osnovanog i uzgajanog zasada topole na definisanom području, čiji je proizvodni ciklus 29 godina. Cilj istraživanja je da se na osnovu troškova $\mathrm{i}$ prihoda $\mathrm{u}$ datom periodu, korišćenjem savremenih principa komercijalne isplativosti, ispitaju finansijski efekti u posmatranom zasadu i proveri njihovo reagovanje na promene u iznosu troškova i prihoda. Osnovna svrha rada je da se ukaže na mogućnosti za unapređenje efikasnosti proizvodnje drveta topole u Srbiji sa stanovišta finansijskih efekata.

\section{MATERIJAL I METOD - Material and Methods}

Kako analiza komercijalne isplativosti predstavlja prvi korak u ekonomskoj oceni projekta (1993), tako se i primenjena metodologija u radu oslanja na savremene metode proračuna isplativosti investicionih ulaganja. Obuhvataju sledeće metode: proste stope prinosa $(S R R)$, period otplate $(P B P)$, neto sadašnju vrednost $(N P V)$, internu stopu prinosa $(I R R)$ i odnos ,korist-trošak“ $(R)$. Sam izbor metoda zavisi od više faktora, kao što su: proizvodni ciljevi preduzeća, ekonomsko okruženje, raspoloživost podataka. $\mathrm{S}$ obzirom na to, u radu su korišćene tri metode: $N P V, I R R$ i $R$. Da bi se utvrdilo kako projekat reaguje na promene troškova i prihoda, $u$ radu je primenjena i metoda analize osetljivosti za $N P V$, IRR i $R$ i na osnovu saznanja o reakciji posmatranih pokazatelja finansijske uspešnosti, potkrepljeni su određeni zaključci.

Neto sadašnja vrednost (NPV) projekta se definiše kao razlika između sadašnjih vrednosti njegovih budućih prihoda i troškova gotovine (GITTINGER, 1972). Obračun se vrši prema sledećoj formuli: 


$$
N P V=\sum_{t=1}^{n}\left(P_{t}-T_{t}\right) \cdot\left(\frac{1}{1+\frac{p}{100}}\right)^{t}
$$

gde su: $N P V$ - neto sadašnja vrednost, $P_{t}$ - gotovinski priliv u godini $t, T_{t}-$ gotovinski odliv u godini $t, p$ - diskontna stopa, $n$ - starost sastojine

Interna stopa prinosa (IRR) je diskontna stopa koja neto sadašnju vrednost projekta svodi na nulu (ZLATIĆ, 1994). Izračunava se prema sledećoj formuli:

$$
0=\sum_{t=0}^{n}\left(P_{t}-T_{t}\right) \cdot\left(\frac{1}{1+\frac{p}{100}}\right)^{t}
$$

Interna stopa prihoda se dobija tako što se iterativnim putem menja diskontna stopa dok se ne dobije rešenje približno traženom uslovu.

Koeficijent rentabilnosti $(R)$ računa se za metodu „korist-trošak“, kao količnik sume sadašnjih vrednosti prihoda i sume sadašnjih vrednosti troškova prema formuli:

$$
R=\frac{\sum P_{r}}{\sum T_{r}}
$$

Da bi projekat bio prihvatljiv od strane investitora, odnos korist-trošak $(R)$ bi po pravilu trebalo da bude veći od 1 (DRAŠKović, 1988).

Analizom osetljivosti posmatrane su promene sadašnjih vrednosti troškova i prihoda u rasponu od 70 do $130 \%$, sa koracima od $5 \%$ i posmatrana je promena finansijske isplativosti projekta, čime se dobijaju rezultati koji ukazuju na pozitive ili negativne efekte. To bi u praksi uticalo na usmeravanje aktivnosti menadžmenta pri izboru odgovarajućeg rešenja za postizanje najpovoljnijih finansijskih rezultata (KEČA ET AL., 2008).

\section{REZULTATI ISTRAŽIVANJA - The results of the study}

Uvidom u osnovne podatke (tabela 1) zapaža se da je trajanje projekta definisano na 29 godina, da je ulaganje u sastojinu bilo u prvih šest godina njene starosti i u 29. godini sastojine (završni sek). Kako su u prvih šest godina odsustvovali prihodi, u sedmoj se primećuje nizak međuprihod, da bi na kraju perioda od 29 godina bio ostvaren prihod od oko $12.630 €\left(438,16 € \cdot h a^{-1}\right)$. 
Tabela 1. Prihodi i troškovi projekta proizvodnje drveta u zasadu topola za $p=12 \%$

Table 1. Receipts and costs of the wood production project in poplar plantation for $p=12 \%$

\begin{tabular}{|c|c|c|c|c|c|c|c|}
\hline \multirow{4}{*}{$\begin{array}{c}\text { Godina } \\
\text { Year }\end{array}$} & \multicolumn{2}{|c|}{$\begin{array}{c}\text { Nominalno } \\
\text { Nominal }\end{array}$} & \multicolumn{2}{|c|}{$\begin{array}{c}\text { Realno } \\
\text { Real }\end{array}$} & \multirow{2}{*}{$\begin{array}{c}\text { Suma } \\
\text { troškova } \\
\text { Costs } \\
\text { sum }\end{array}$} & \multirow{2}{*}{$\begin{array}{c}\text { Suma } \\
\text { prihoda } \\
\text { Receipts } \\
\text { sum } \\
\end{array}$} & \multirow{3}{*}{$\sum \boldsymbol{P}_{\mathbf{r}}-\sum \boldsymbol{T}_{\mathbf{r}}$} \\
\hline & $\begin{array}{c}\text { Trošak } \\
\text { Costs }\end{array}$ & $\begin{array}{l}\text { Prihod } \\
\text { Receipts }\end{array}$ & $\begin{array}{c}\text { Trošak } \\
\text { Costs }\end{array}$ & $\begin{array}{l}\text { Prihod } \\
\text { Receipts }\end{array}$ & & & \\
\hline & $T$ & $P$ & $T_{\mathrm{r}}$ & $P_{\mathrm{r}}$ & $\sum \boldsymbol{T}_{\mathrm{rs}}$ & $\sum \boldsymbol{P}_{\mathrm{rs}}$ & \\
\hline & \multicolumn{7}{|c|}{$€$} \\
\hline 0 & $2.040,48$ & 0,00 & 2040,48 & 0,00 & $2.040,48$ & 0,00 & \begin{tabular}{|l|}
$-2.040,48$ \\
\end{tabular} \\
\hline 1 & 209,44 & 0,00 & 187,00 & 0,00 & $2.227,48$ & 0,00 & \begin{tabular}{|l|}
$-2.227,48$ \\
\end{tabular} \\
\hline 2 & 177,97 & 0,00 & 141,88 & 0,00 & $2.369,36$ & 0,00 & 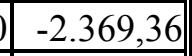 \\
\hline 3 & 111,65 & 0,00 & 79,47 & 0,00 & $2.448,83$ & 0,00 & $-2.448,83$ \\
\hline 4 & 96,90 & 0,00 & 61,58 & 0,00 & $2.510,41$ & 0,00 & $-2.510,41$ \\
\hline 5 & 96,90 & 0,00 & 54,98 & 0,00 & $2.565,39$ & 0,00 & $-2.565,39$ \\
\hline 6 & 442,22 & 1.064 .2 & 224,04 & 539,16 & $2.789,43$ & 539,16 & \begin{tabular}{|l|}
$-2.250,28$ \\
\end{tabular} \\
\hline 29 & $2.529,66$ & 12.627 .73 & 94,57 & 472,07 & $2.884,00$ & $1.011,22$ & \begin{tabular}{|l|}
$-1.872,78$ \\
\end{tabular} \\
\hline $\boldsymbol{\Sigma}$ & 1 & 1 & $2.884,00$ & $1.011,22$ & I & 1 & l \\
\hline
\end{tabular}

Neto sadašnja vrednost (NPV) projekta, pri diskontnoj stopi od $12 \%$ iznosi $N P V=\Sigma P_{\mathrm{r}}-\Sigma T_{\mathrm{r}}=-1.872,78 €\left(\approx-65 € \cdot h a^{-1}\right)$. Na osnovu toga može se zaključiti da je projekat za vremenski period od 29 godina i diskontnu stopu od $12 \%$ praktično neisplativ, jer na kraju ciklusa iskazuje gubitak od oko $1.900 €$. Stoga bi rešenja trebalo tražiti u obračunu sa nižom kamatnom stopom ili ispitati mogućnost skraćenja proizvodnog ciklusa.

Da bi projekat bio prihvatljiv od strane investitora, odnos „korist trošak“ bi trebao da bude iznad 1 (KEČA, 2005). U ovom slučaju je on 0,35 , što znači da su troškovi projekta pri diskontnoj stopi od $12 \%$ oko 3 puta veći od prihoda i da svaki dinar ulaganja donosi 0,35 dinara prihoda, odnosno 0,65 dinara gubitka. Može se zaključiti da je projekat i prema ovome kriterijumu neisplativ.

Interna stopa prinosa (IRR) iznosi 5,41, iz čega se može zaključiti da je godišnja stopa prihodovanja samo $5,41 \%$ od ukupnog investicionog ulaganja. Shodno tome, može se zaključiti da je ovakav projekat nemoguće kreditno otplaćivati, ako bi se finansiranje ovakve investicije obavljalo putem nekog kreditnog aranžmana. Kao rešenje moglo bi se predložiti eventualno smanjenje kamatne stope na iznos jednak ili manji od $5,41 \%$. 
Tabela 2. Osetljivost $N P V$ u odnosu na relativne promene $T_{\mathrm{r}}$ i $P_{\mathrm{r}}(p=4-12 \%)$

Table 2. Susceptibility of $N P V$ depending on relative changes of $T_{\mathrm{r}}$ and $P_{\mathrm{r}}(p=4-12 \%)$

\begin{tabular}{|c|c|c|c|c|c|c|c|c|}
\hline \multirow{2}{*}{$\begin{array}{c}\text { Stopa promene } \\
\text { Change rate }\end{array}$} & \multicolumn{2}{|c|}{$p=12 \%$} & \multicolumn{2}{|c|}{$p=8 \%$} & \multicolumn{2}{|c|}{$p=6 \%$} & \multicolumn{2}{|c|}{$p=4 \%$} \\
\hline & $T_{\mathrm{r}}$ & $P_{\mathrm{r}}$ & $T_{\mathrm{r}}$ & $P_{\mathrm{r}}$ & $T_{\mathrm{r}}$ & $P_{\mathrm{r}}$ & $T_{\mathrm{r}}$ & $P_{\mathrm{r}}$ \\
\hline$\%$ & \multicolumn{8}{|c|}{$€ \cdot 10^{-3}$} \\
\hline 70 & $-1,01$ & $-2,18$ & $-0,19$ & $-1,74$ & 0,69 & $-1,26$ & 2,21 & $-0,41$ \\
\hline 75 & $-1,15$ & $-2,13$ & $-0,35$ & $-1,64$ & 0,52 & $-1,11$ & 2,02 & $-0,16$ \\
\hline 80 & $-1,30$ & $-2,08$ & $-0,50$ & $-1,54$ & 0,35 & $-0,95$ & 1,83 & 0,08 \\
\hline 85 & $-1,44$ & $-2,02$ & $-0,66$ & $-1,44$ & 0,18 & $-0,80$ & 1,64 & 0,33 \\
\hline 90 & $-1,58$ & $-1,97$ & $-0,82$ & $-1,34$ & 0,00 & $-0,65$ & 1,44 & 0,57 \\
\hline 95 & $-1,73$ & $-1,92$ & $-0,98$ & $-1,24$ & $-0,17$ & $-0,49$ & 1,25 & 0,82 \\
\hline 100 & $-1,87$ & $-1,87$ & $-1,14$ & $-1,14$ & $-0,34$ & $-0,34$ & 1,06 & 1,06 \\
\hline 105 & $-2,02$ & $-1,82$ & $-1,30$ & $-1,04$ & $-0,51$ & $-0,18$ & 0,87 & 1,31 \\
\hline 110 & $-2,16$ & $-1,77$ & $-1,45$ & $-0,93$ & $-0,68$ & $-0,03$ & 0,68 & 1,55 \\
\hline 115 & $-2,31$ & $-1,72$ & $-1,61$ & $-0,83$ & $-0,85$ & 0,12 & 0,49 & 1,79 \\
\hline 120 & $-2,45$ & $-1,67$ & $-1,77$ & $-0,73$ & $-1,02$ & 0,28 & 0,30 & 2,04 \\
\hline 125 & $-2,59$ & $-1,62$ & $-1,93$ & $-0,63$ & $-1,19$ & 0,43 & 0,10 & 2,28 \\
\hline 130 & $-2,74$ & $-1,57$ & $-2,09$ & $-0,53$ & $-1,36$ & 0,59 & $-0,09$ & 2,53 \\
\hline Uslov za $\sum \boldsymbol{P}_{\mathrm{r}}-\sum \boldsymbol{T}_{\mathrm{r}}=\mathbf{0}$ & 35,06 & 285,20 & 64,05 & 156,12 & 90,13 & 110,95 & 127,72 & 78,30 \\
\hline
\end{tabular}

Analizom osetljivosti utvrđeno je kako projekat reaguje na promene troškova i prihoda, variranjem promena troškova i prihoda u rasponu $\pm 30 \%$ (u koracima od po $5 \%$. $\mathrm{Na}$ osnovu toga se može videti kakva je perspektiva projekta u datom vremenskom periodu u slučaju nepredviđenih promena koje se odražavaju na prihode ili troškove (tabela 2).

Utvrđeno je da bi za $p=12 \%$ projekat bio isplativ tek u slučaju da je moguće ostvarenje povećanja prihoda za više od 2,8 puta (285\%) ili da je moguće smanjenje troškova za oko $65 \%$. Za $p=8 \%$ potrebno je smanjiti troškove za oko $36 \%$ da bi investicija pokrila troškove iz prihoda. Alternativni način je da se pri postojećim uslovima prihod poveća za oko $56 \%$. Za $p=6 \%$ pri postojećim uslovima i prihodima, potrebno je smanjiti troškove za oko $10 \%$ (ostvariti iznos od $94 \%$ od načinjenih troškova) da bi investicija pokrila troškove iz prihoda. Moguće je isti finansijski efekat ostvariti pri postojećim uslovima i troškovima, uz povećanje prihoda od $11 \%$. Za $p=4 \%$ moguće je da investicija pokrije troškove iz prihoda čak i pri uvećanju troškova za oko $28 \%$. Pri načinjenim troškovima i postojećim uslovima, može se uz smanjenje prihoda za 22\% (78\% od ostvarenog) obezbediti isti finansijski efekat (grafikon 1). 
Grafikon 1. Promena sadašnjih vrednosti prihoda i troškova za $p=12,8,6$ i 4\%

Diagram 1. Changes of the present value of receipts and costs for $p=12,8,6$ and $4 \%$
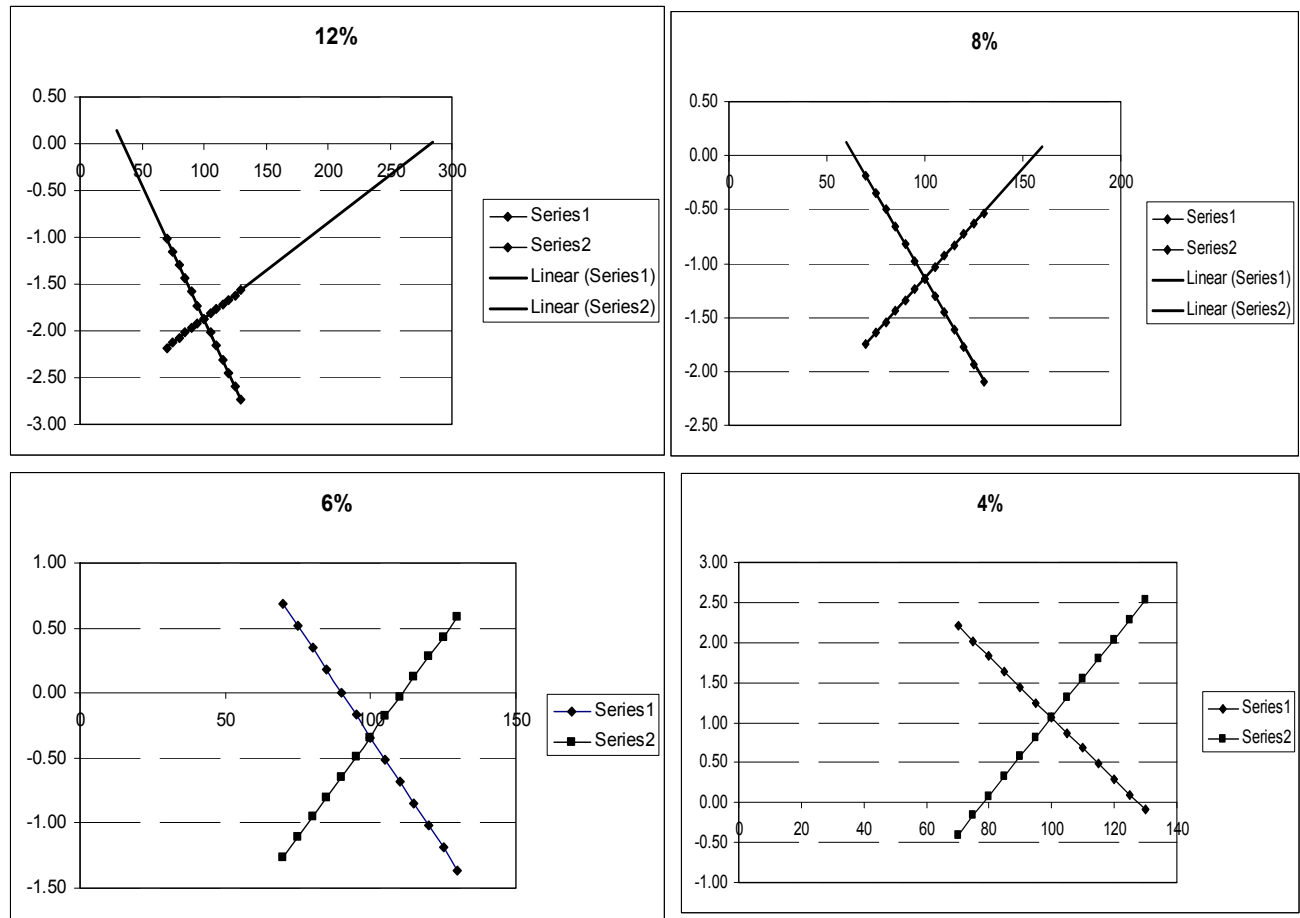

Kada se radi o promeni interne stope prinosa (tabela 3), nisu konstatovani iznosi $I R R$ veći od $12 \%$ u posmatranom rasponu promena troškova i prihoda, već se oni ostvaruju na nivou ispod $70 \%$ od ostvarenih troškova $(\leq 35 \%)$ ili iznad $130 \%$ od ostvarenih prihoda ( $\geq 285 \%$ ) (tabela 3 ). (tabela 4$)^{3}$.

Odnos "korist-trošak" za $p=12 \%$ u posmatranom rasponu $T_{\mathrm{r}}$ i $P_{r}$ manji je od 1

Da bi se pronašlo optimalno rešenje pri upućivanju menadžmenta preduzeća na usmeravanje finansijskih sredstava ka smanjenju troškova ili povećanju prihoda, posmatrani su granični iznosi $I R R, N P V$ i $R$ za relativne promene sadašnje vrednosti troškova i prihoda u rasponu $70-130 \%$ pri diskontnoj stopi od 12\% (tabela 5).

${ }^{3}$ Postoje slučajevi kada je pri određenom stepenu smanjenja troškova, odnosno povećanja prihoda za $p=4-6 \%$, ovaj odnos veći od 1 (KEČA, 2008) 
Tabela 3. Osetljivost $I R R$ u odnosu na relativne promene $T_{\mathrm{r}}$ i $P_{\mathrm{r}}$

Table 3. Sensitivity of $I R R$

\begin{tabular}{||c|r|r||}
\hline \hline \multirow{2}{*}{$\begin{array}{c}\text { Stopa promene } \\
\text { Change rate }\end{array}$} & \multicolumn{1}{|c|}{$\boldsymbol{T}_{\boldsymbol{r}}$} & \multicolumn{1}{|c|}{$\boldsymbol{P}_{\boldsymbol{r}}$} \\
\cline { 2 - 3 } $\mathbf{\%}$ \\
\hline \hline 70 & 7,47 & 3,35 \\
\hline 75 & 7,06 & 3,75 \\
\hline 80 & 6,69 & 4,13 \\
\hline 85 & 6,34 & 4,47 \\
\hline 90 & 6,01 & 4,80 \\
\hline 95 & 5,70 & 5,11 \\
\hline 100 & 5,41 & 5,41 \\
\hline 105 & 5,13 & 5,68 \\
\hline 110 & 4,86 & 5,95 \\
\hline 115 & 4,60 & 6,21 \\
\hline 120 & 4,36 & 6,45 \\
\hline 125 & 4,13 & 6,69 \\
\hline 130 & 3,90 & 6,92 \\
\hline $\boldsymbol{I R R}=\mathbf{1 2} \%$ & $\mathbf{3 5 , 0 6}$ & $\mathbf{2 8 5 , 2 0}$ \\
\hline
\end{tabular}

Tabela 4. Osetljivost $R$ u odnosu na relativne promene $T_{r}$ i $P_{r}$

Table 4. Sensitivity of $R$

\begin{tabular}{|c|r|r||}
\hline Stopa promene & \multicolumn{1}{|c|}{$\boldsymbol{T}_{\boldsymbol{r}}$} & \multicolumn{1}{c|}{$\boldsymbol{P}_{\boldsymbol{r}}$} \\
\cline { 2 - 3 } Change rate & \multicolumn{2}{|c|}{$\boldsymbol{~}$} \\
\hline \hline 70 & 0,51 & 0,25 \\
\hline 75 & 0,47 & 0,26 \\
\hline 80 & 0,44 & 0,28 \\
\hline 85 & 0,41 & 0,30 \\
\hline 90 & 0,39 & 0,32 \\
\hline 95 & 0,37 & 0,33 \\
\hline 100 & 0,35 & 0,35 \\
\hline 105 & 0,33 & 0,37 \\
\hline 110 & 0,32 & 0,39 \\
\hline 115 & 0,31 & 0,40 \\
\hline 120 & 0,29 & 0,42 \\
\hline 125 & 0,28 & 0,44 \\
\hline 130 & 0,27 & 0,46 \\
\hline $\boldsymbol{R}=\mathbf{1}$ & $\mathbf{3 5 , 0 6}$ & $\mathbf{2 8 5 , 2 0}$ \\
\hline
\end{tabular}

Tabel a 5. Uticaj promena $I R R, N P V$ i $R$ na relativne promene $T_{\mathrm{r}}$ i $P_{\mathrm{r}}$ za $p=12 \%$

Table 5. Effects of changes of $I R R, N P V$ and $R$ on the relative changes of $T_{\mathrm{r}}$ and $P_{\mathrm{r}}$

\begin{tabular}{|c|c|c|c|c|c|c|c|c|c|}
\hline $\boldsymbol{P}_{\mathrm{r}}$ & $T_{\mathrm{r}}$ & IRR & $N P V$ & $R$ & $\boldsymbol{P}_{\mathrm{r}}$ & $T_{\mathrm{r}}$ & IRR & \multirow{2}{*}{$\begin{array}{l}N P V \\
€ \cdot 10^{-3}\end{array}$} & \multirow{2}{*}{$R$} \\
\hline \multicolumn{3}{|c|}{$\%$} & $\epsilon \cdot 10^{-3}$ & 10 & \multicolumn{3}{|c|}{$\%$} & & \\
\hline \multirow{2}{*}{100} & 70 & $\overline{7,47}$ & $-1,01$ & 0,51 & \multirow{2}{*}{100} & 70 & 3,35 & $-2,18$ & 0,25 \\
\hline & 130 & 3,90 & $-2,74$ & 0,27 & & 130 & 6,92 & $-1,57$ & 0,46 \\
\hline
\end{tabular}

$\mathrm{Na}$ osnovu tih podataka zaključuje se da je projekat osetljiviji na promene troškova nego na promene prihoda, pa je u ovom slučaju svrsishodnije usmeriti napore menadžmenta u pravcu smanjenja troškova proizvodnje ( $u$ proizvodnim fazama, prilikom obrade zemljišta, poboljšati organizaciju rada na terenu i sl.), nego povećanja prihoda.

\section{DISKUSIJA - Discusion}

Iz prethodnih istraživanja (RANKOVIĆ, 1996) je poznato da bi se efekat nepovoljne diskontne stope od $12 \%$ mogao prevazići smanjenjem dužine proizvodnog ciklusa ispod 20 godina, što bi obezbedilo pozitivan finansijski efekat ovakvih i sličnih projekata. U topolarstvu bi trebalo aktivirati i druge proizvodne aktivnosti, tj. proizvodnju nekih drugih produkata, čime bi se značajno povećala prihodna strana projekata. U Italiji se praktikuje sadnja kestena, što se u finansijskom smislu pokazalo 
kao veoma atraktivno. U cilju podsticanja proizvođača ka podizanju veštačkih zasada topole (naročito u privatnom sektoru) investitorima se može predložiti da se uvedu niže kamatne stope na pozajmljena sredstva (ispod 10\%), čime bi se obezbedilo finansiranje ovakvih projekata. Ovakva rešenja imaju ne samo privredni, nego i širi društveni značaj. Od širih društvenih interesa (MAYERS, BASS, 2004) mogu se kao najznačajniji izdvojiti: povećanje površine pod šumom, ekološki dobici, sigurnije snabdevanje tržišta drvnom sirovinom i sl.

\section{ZAKLJUČCI - Conclusion}

Iz prethodne analize može se zaključiti sledeće:

- pri diskontnoj stopi od $12 \%$ projekat je za trajanje proizvodnog ciklusa od 29 godine neisplativ, jer se nalazi u gubitku od oko $1.900 €$;

- navedena neisplativost projekta je potvrđena i analizom „koristtrošak", pošto su troškovi projekta pri diskontnoj stopi od $12 \%$ skoro 3 puta veći od prihoda $(R=0,35$, odnosno prihodi čine tek $35 \%$ od troškova);

- interna stopa prinosa je 5,41\% (projekat uvećava prihode prosečno godišnje za taj iznos), što je znatno ispod kalkulativne diskontne stope od $12 \%$, pa bi finansiranje pomoću nekog kreditnog aranžmana bilo jako otežano;

- primenom analize osetljivosti utvrđeno je da postoji određeni prostor da se smanjivanjem troškova ili povećanjem prihoda ostvari pozitivan finansijski efekat;

- umanjenje troškova u većoj meri utiče na finansijski efekat proizvodnje nego povećanje prihoda u posmatranom slučaju.

\section{LITERATURA - References}

(1993): Integrating Environment and Economics - The Role of Economic Instruments, OECD, Paris.

DRAŠKOVIĆ, B. (1998): Ekonomija prirodnog kapitala, „Vrednovanje i zaštita prirodnih resursa“, Institut ekonomskih nauka, Beograd (429).

GitTinger, P. (1972): Economic Analysis of Agricultural Projects, The Economic Institute, International Bank for Reconstruction of Development, The John Hopkins University Press, Baltimore - London (275).

Gregersen, H., Contreras, A. (1979): Economic Analysis of Forestry Projects, FAO Forestry Paper 17, p. 194.

KEČA, LJ. (2005): Analiza komercijalne isplativosti topolovih zasada, Glasnik Šumarskog fakulteta, Beograd (135-147). 
KeČA, LJ., Ranković, N., PAJIĆ, S. (2008): Analiza komercijalne isplativosti zasada topola starosti 24 godine, Glasnik Šumarskog fakulteta 97, Univerzitet u Beogradu Šumarski fakultet, Beograd (171-186).

MAYers,, J., BAss S. (2004): Policy That Works for Forests and People, Earthscan, United Kingdom, p. 324.

PUDAR, Z. (1982): Ekonomski aspekti ostvarenih prinosa u zasadima topole, P. ×euramericana (Dode) Guinier, kl. I-214 sa dva razlicita razmaka sadnje, Knjiga 13, Institut za topolarstvo, Novi Sad (126).

RANKOVIĆ, N. (1996): Ekonomika šumarstva, Šumarski fakultet Univerziteta u Beogradu, (362 s.).

ZLATIĆ, M. (1994): Vrednovanje protiverozionih radova sa aspekta tehničke $i$ ekonomske opravdanosti na ugroženom području grada Beograda, doktorska disertacija u rukopisu, Univerzitet u Beogradu - Šumarski fakultet, Beograd (25-28).

\section{SUMMARY - Sažetak}

Poplar growing has been expanded during the last decades, because poplar wood has a series of advantages compared to other tree species, which first of all have a very long rotation. Based on the method of analysis of commercial costeffectiveness, this study resulted in the conclusions which could be used in future, especially in practice.

The study was based on the data of receipts and expenses in the Management Unit ,Rađenovići Novi", compartment 20a (FE ,Sremska Mitrovica"). By the above methods, it was concluded that the project middle-rotation poplar growing in this case is altogether unacceptable. Namely, under the discount rate of $12 \%$ and for the time period of 29 years, the project is unprofitable, the loss is even $€ 1,900$. Unprofitability of the project is confirmed by "cost-benefit" analysis, because the project expenses under the discount rate of $12 \%$, are about 3 times higher than the receipts. Internal rate of return is $5.41 \%$, meaning that only $5.41 \%$ of the total capital will be returned, i.e. in 29 years. The possible recommended solution can be the lowering of the interest rate to the amount equal to or lower than $5.41 \%$. By the application of the susceptibility analysis, it was concluded that there was an option to realize the positive financial effect by decreasing the costs or by increasing the receipts. .

In practice it is necessary to improve the position of producers in getting the deficient financial means for the investment in poplar cultivation, so as to stimulate the establishment of artificial poplar plantations, especially in the private sector (on private land which are unattractive for agriculture production). 